\title{
The Early Emergence of Temporal Reference in Mother-Child Multimodal Communication*
}

\section{Emergencia temprana de la referencia temporal en la comunicación multimodal entre madre-niño}

Recibido: enero 28 de 2013 | Revisado: enero 13 de 2014 | Aceptado: enero 13 de 2014

\author{
MERCEDES AMPARO MUÑETÓN ** \\ Universidad de Antioquia, Colombia \\ MARÍA JOSÉ RODRIGO**** \\ Universidad de La Laguna, Tenerife, España
}

doi:10.11144/Javeriana.UPSY13-3.teer

Para citar este artículo: Muñetón, M. A., \& Rodrigo, M. J. (2014). The early emergence of temporal reference in mother-child multimodal communication. Universitas Psychologica, 13(3), 1123-1134. http://dx.doi.org/10.11144/Javeriana.UPSY13-3.teer

* This research was funded by the Spanish Ministry of Economy and Competitivity (PSI 2012-32879) and by the NEUROCOG project supported by the Canarian Agency for Research, Innovation and the Information Society and the European Regional Development Funds to María José Rodrigo.

** Profesora Asociada de Psicolingüística en la Facultad de comunicaciones, programa Filología Hispánica, Universidad de Antioquia. E-mail: mamuneton@hotmail.com

**** Profesora del Departamento de Psicología Evolutiva y de la Educación, Facultad de Psicología, Campus de Guajara, Universidad de La Laguna, Tenerife, España.E-mail: mjrodri@ull.es

\begin{abstract}
A B S T R A C T
The study longitudinally explores the early emergence of temporal reference to objects/events that are either present or absent in time while mothers and children use and combine pointing and verbal references. Over one year of observations and in five separate sessions, eight Spanish mothers and their one- and two-year-old babies were observed while performing daily routines at home. The results indicated that overall mothers and children used more verbs referring to the present frame than to the past and future frames. As compared with the production of utterances accompanied by pointing, children were more likely to produce present references in the young group and displaced references (mostly near past and near future) in the older group when utterances were produced without pointing. Mothers closely preceded or accompanied the children's verbal and gestural referential production to either immediate or displaced referents across ages, indicating that they systematically engage their children in talking about the present and especially about the future.

Keywords

immediate and displaced reference; temporal reference; mother and child multimodal communication

\section{RESUMEN}

El estudio explora de forma longitudinal la aparición temprana de la referencia temporal de los objetos/eventos que están presentes o ausentes en el tiempo, mientras que las madres y los niños usan y combinan señales y referencias verbales. Más de un año de observaciones y en cinco sesiones separadas, ocho madres españolas y sus bebés de uno y dos años de edad se observaron en el desempeño de las rutinas diarias en el hogar. Los resultados indicaron que las madres en general y los niños utilizan más verbos que se refieren al marco actual que a las situaciones pasadas y futuras. En comparación con la producción de los enunciados acompañados de señalar, los niños eran más propensos a producir referencias presentes en el grupo de jóvenes y referencias desplazadas (en su mayoría cerca de pasado y futuro cercano) en el grupo de mayor edad cuando se produjeron declaraciones sin apuntar. Las madres más facilmente precedian o acompañaban de forma verbal y gestual la producción referencial de los niños ya sea a los referentes inmediatos o desplazadas en todas las edades, lo que indica que se dedican sistemáticamente a sus hijos en hablar sobre el presente y especialmente sobre el futuro.

Palabras clave

referencia inmediata y desplazada; referencia temporal; comunicación multimodal madre e hijo
\end{abstract}


Mother and child move in a rich referential space while engaging in everyday routines in natural settings. This communicative environment is very complex involving a multimodal flow of communication involving gestural and verbal means (Meltzoff \& Kuhl, 1994) and many targets (objects and events) as potential referents. These objects and events may or not be present in the child's temporal frame. This study systematically addresses the early emergence of temporal reference by longitudinally exploring how mother and child during the second and third years of life combine the use of utterances with verbs and pointing gesture to refer to events that are either present or absent in time. The presence of pointing plus speech combinations has been reported in the early stages of child development (Özçalışkan \& Goldin-Meadow, 2009) but there is no evidence with respect to their use in temporal references. In turn, the role played by the mother in supporting her child's use of gestural and verbal references to objects and events in multimodal communication has been largely neglected in research. We first review studies on the child's use of temporal reference and then those emphasizing the role of mothers in the referential process to back up our proposals.

Several studies have shown the existence of a delay between production and comprehension in the early acquisition of the present and past tenses in verbs. English-speaking two- and three-year-olds often produce verbs with no visible tense marking, whether in spontaneous speech or imitation (Valian \& Aubry, 2005, where two-year-olds imitated regularly inflected past tense verbs between $2 \%$ to $14 \%$ of the time), or elicited production (Schütze \& Wexler, 2000, where three-year-olds produced the past tense less than half the time). Further, in early language acquisition, both copula (is/was) and progressive (-ing) forms are often absent (Wilson, 2003). By contrast, in an elicited comprehension task, the two-year-olds successfully distinguished the auxiliaries will/did and the copula is/was, while performing marginally on the progressive form. The three-yearolds successfully distinguished copula, auxiliary and progressive forms, and finally, the four-year-olds performed at ceiling on all forms (Valian, 2006).

Mothers would appear to actively support their child's immediate gestural and verbal references, a facet of 'motherese' or child-directed speech that has received little attention (Gallaway \& Richards, 1994). Mothers would appear to play an important role in supporting their child's displaced reference by naming objects outside their immediate temporal context (Harris, Jones, \& Grant, 1983). Lewis (1934) reported that early child references to the non-present objects or events often take the form of responses to adults' questions, and Sachs (1983) found that parent-elicited references to the past and future precede the child's spontaneous talk about the past and future by three to six months. Parents initiated displaced communication more often when talking about distal and non-actual events, and more often when talking about the past than about the future (Eisenberg, 1985; Morford \& Goldin-Meadow, 1997). However, studies by Lucariello and Nelson (1987) and by Benson (1997) indicate that parents talk with young children about the future as much as or even more than they talk about the past.

Convergent linguistic evidence from a mother-child comparison of the use of Spanish verbs in a child from 19 months to 26 months shows that the inflexion forms used by the mother already showed the same biases as the child's distribution of inflected forms: the present, infinitives, and imperatives are used first, followed by various forms of the past, whereas the future forms were the least used (Rojas, 2003). Likewise, a mother-child comparison study with verbs in French showed that the particular form children used for a given verb corresponded to the one mothers predominantly used when talking to their children (Veneziano \& Parisse, 2010).

In this study we asked two research questions: 1) the role played by the combined use of pointing plus speech in the transition from immediate to displayed reference, and 2) to what extent the mother, who is cognitively more advanced than her child, developmentally adapt to the child's competence to refer to immediate or absent entities in time. We undertake a longitudinal comparison of the use, by mothers and children from one year to three years olds, of verbal and gestural references to objects that are either present or absent in time during the performing of everyday routines. In these settings, the likelihood is great that one will observe both combined and single uses of 
verbal references and pointing gestures across many instances of mother-child communication. In addition, the longitudinal data obtained across two age groups, each of which was observed at five different points in time, would be of considerable assistance in tracing the mother-child spontaneous temporal referencing.

A comparison was made of the percentage of utterances, accompanied or not with a pointing gesture, containing action verbs referring to the following five temporal frames: present, near past, far past, near future and far future. Based on these comparisons, we examined whether the distribution of these categories of verbal reference was similar for mothers and children. We also examined the developmental trends in the child's use of time references. We expected that younger children aged 1 to 2 would be less able to use the displaced reference than older children aged 2 to 3. As for the mothers, we expected to find a similar developmental trend as a signal of a mother-child co-development of verbal reference.

\section{Method}

\section{Participants and Procedure}

Four one-year-old infants and their mothers (the younger group) and four two- year-old children and their mothers (the older group) were followed for 12 months. The mean age of the children in Group 1 was 24.4 months $(S D=0.2)$ and the mean age of children in Group 2 was 24.3 months (SD $=0.1$ ) at the time of first observation session. None of the children exhibited any abnormalities in cognitive development. All children were first-born, and all had mothers (mean age 29, range 26-34 years, for both groups) with a university education and socioeconomic status ranging from medium to high. Four children had mothers who worked outside the home, and four children had mothers working at home (half in each age group). Table 1 gives each child's gender, the age period studied, the number of home sessions, the total number of videotaped minutes and the number of utterances produced containing verbal references, whether accompanied or not by a pointing gesture. The total observation time was 14.3 hours for Group 1 and 14.2 hours for Group 2. Overall, the children produced fewer utterances (5362) than their mothers (20.791). There were fewer utterances with pointing than without pointing (390 and 4972 for the child; 5564 and 15.227 for the mother, respectively).

Over the course of 12 months, with an interval of three months between sessions in each group (five sessions per dyad), video recordings were made of activity sequences consisting of daily routines of free play, followed by bathing, and finally eating dinner. Mothers were instructed to interact and play with their children like they normally would; meanwhile, the observer avoided interfering with mother-child interactions. The same observer recorded all sessions for each dyad and before the study began, the observer visited the home three times to allow the child to become acclimatized to her.

\section{TABLE 1}

Comparative Data on the Children and the Mothers

\begin{tabular}{ccccccccc}
\hline & & & & \multicolumn{3}{c}{ Child } & \multicolumn{2}{c}{ Mother } \\
\hline Child & Age period & Sex & $\begin{array}{c}\text { No. of } \\
\text { sessions }\end{array}$ & $\begin{array}{c}\text { Total } \\
\text { time }\end{array}$ & $\begin{array}{c}\text { Utteranceswith } \\
\text { pointing }\end{array}$ & $\begin{array}{c}\text { Utterances } \\
\text { without pointing }\end{array}$ & $\begin{array}{c}\text { Utterances with } \\
\text { pointing }\end{array}$ & $\begin{array}{c}\text { Utterances } \\
\text { without pointing }\end{array}$ \\
\hline PA & 1 to 2 & F & 5 & $220^{\prime}$ & 18 & 147 & 161 & 354 \\
LA & 1 to 2 & F & 5 & $186^{\prime}$ & 5 & 89 & 137 & 1274 \\
JP & 1 to 2 & M & 5 & $185^{\prime}$ & 7 & 54 & 77 & 900 \\
CA & 1 to 2 & M & 5 & $271^{\prime}$ & 5 & 120 & 185 & 1418 \\
PC & 2 to 3 & F & 5 & $141^{\prime}$ & 60 & 1271 & 1343 & 3906 \\
CR & 2 to 3 & M & 5 & $271^{\prime}$ & 88 & 464 & 547 & 1051 \\
PB & 2 to 3 & M & 5 & $196^{\prime}$ & 100 & 1440 & 1581 & 3668 \\
CE & 2 to 3 & M & 5 & $244^{\prime}$ & 107 & 1387 & 1533 & 2656 \\
\hline
\end{tabular}

Source: own work 


\section{Data Coding}

A transcription was made from the videotapes of the flow of verbal and gestural interactions observed during play, bath and dinner routines for each dyad and at each age-point. The transcriptions preserved the sequence of production of utterances by mother and child and included information about the speaker who had initiated the interaction, any vocalizations or speech and the occurrence of a pointing gesture. We did not classify the utterances for grammatical complexity, as we were only interested in the referential production, but utterances varied from simple vocalizations with communicative intentions (child says ga-ga looking at a biscuit), one-word utterances (child says agua, agua 'water, water' while bathing) or two-word utterances (child says papi, bien 'daddy nice'), to complex utterances including more than one verb (mother says mientras se llena el baño con agua, quédate aquí y quitate la camisa, "While the bath is being filled with water, stay here and take off your shirt', child says Mira aquí mira, no se ve el osito, no se ve el osito 'look over here look, the teddy bear cannot be seen, the teddy bear cannot be seen'). In the case of complex utterances, we subdivided the utterances into several clauses, with each one including a subject, a main verb, and a referred object/person/event. When the utterance was not comprehensible, brackets were placed around it in the transcription.

For the gestural reference, the production of pointing gestures was recorded in the transcription. A pointing gesture was defined as an outstretched arm with the index finger extended toward an object or a person. As part of the flow of interactions, an indication that a pointing gesture had been produced was inserted into the transcription within the corresponding utterance; this enabled us to further analyze the mother and child utterances accompanied or not by a pointing gesture. Cases in which the pointing gesture was produced in silence were extremely negligible and were not considered in the analyses.

\section{Coding Temporal References}

We classified all utterances according to their temporal references, searching for instances of immediate and displaced reference. A displaced reference was defined as any utterance that directed the interlocutor's attention toward some information that was not perceptible in the environment of the communicators (Hockett, 1960). Categories of temporal reference were coded in terms of the temporal frame of reference indicated by the main verb in the utterance (Hudson, 2002). We concentrated on verbs only and not on temporal adverbs in order to simplify the coding. Five categories of temporal reference used to situate objects, persons and events were coded: a) present frame: when the object, person or event referred to was present or taking place during the communicative act. This was usually indicated by present, infinitive and imperative inflexions (the mother says: este escribe 'this writes' referring to a pen; the child says: el ojo está aquí 'the eye is here' while he points to his eye); b) near past frame: when the object, person or event referred to took place or was present just prior to the communicative act and still during the observation session (mother says: ¿quién bebió agua? 'who drank water?'; child says: esto me gustó 'I liked this' when he had finished eating); c) far past frame: when the object, person or event referred to took place or was present in the past, and not during the observation session (mother says: esto fue ayer 'it was yesterday'; children says: sí, yo jugué 'yes, I played'). This could include the use of suffixes such as: ' $-b a$ ' to form the imperfect (cant-a-ba) or '-é' or '-ado' to form the past (cant-é or he cant-ado); d) near future frame: when the temporal frame of the object, person or event referred to was after the communicative act but still during the session. This could include the use of suffixes or syntactical structures indicating the future, such as: '-ré' or 'voy a' (I am going to), respectively (mother says: icuál de ellos me vas a dar? 'which one are you going to give me?'; child says: Sí, me voy a dormir 'yes, I am going to sleep'); and e) far future frame: when the temporal frame of the object, person or event referred to was after the communicative act and not during the observation session. In general, these used the inflexion '-ré' (mother says: jugaré contigo 'I will play with you'; child says: lo pondré luego 'I will 
put it there after'). Many of the younger children's utterances could not be reliably coded for temporal reference, because they consisted of a word or short phrase that did not include a verb. In this case, they were not coded as temporal references but placed between brackets in the corresponding transcripts for that child/session. When the tense of the verb could not be determined (e.g. there was no temporal inflection) or the verb inflection was grammatically incorrect, the temporal frame was coded taking into account the general flow of the mother-child communication. In this way, we avoided the risk of underestimating the younger children's referential capabilities due to their problems in mastering the grammatical complexities of verbs (Veneziano \& Parisse, 2010).

\section{Reliability}

Two independent coders rated all the home sessions for each dyad and the utterances with and without pointing across the different ages. Inter-rater reliabilities (Kappa coefficient) for the five categories of temporal reference were: 0.94 (present frame), 0.9 (near past frame), 0.87 (far past frame), 0.92 (near future frame), and 0.86 (far future frame).

\section{Results}

We began by describing the emerging patterns of the five categories of temporal reference in mother and child across the five observation points in each age group, addressing the utterances with and without pointing separately. Then, we compared the percentages of use of the five categories of temporal reference in the mother and child data, both overall and separately by group and by utterances with and without pointing. Next, we analyzed the correspondence between the percentages in mothers and children of utterances in each category of temporal reference across the ten observation points spanning the two age groups. In these analyses the contribution of pointing was partialled out to discover to what extent the presence of pointing gestures modulate the use of displaced referents both in the mother and child across ages.
Table 2 displays the percentage of utterances with and without pointing produced at each observation session by children and mothers corresponding to the five categories of temporal reference. Data from free-play, bath and dinner episodes were collapsed herein, given that there were no significant differences in the production of references. Percentages were calculated with respect to the total number of utterances containing temporal references produced by mothers and children, respectively. The accumulated percentages of the four children and the four mothers were calculated at each observation point. Overall, both mothers and children used more verbs referring to the present frame than to the past and future frames. Mothers and children produced more utterances without pointing than with pointing, as could be expected.

Concerning the references to the present frame, the child's first reference to a present frame in utterances with pointing was in session 5 (24 months). By contrast, in utterances without pointing, children were able to use the present frame from session 1 (12 months) and increased their use to session 5 (24 months). Mothers used the present frame from the first session, under both conditions (with and without pointing). The use of references to the present frame was very robust, as it seems to gradually increase from 24 months onward in both mothers and children, under the two conditions.

Concerning references to the past and future, younger children did not produce any reference to either (there was only one reference to the near future in session 4), irrespective of the condition under which the utterance was being made. In mothers, there were also practically no references to the past in utterances with pointing, although there were a few references to the near future (albeit only starting in session 2), and very few to the far future.

By contrast, in utterances without pointing, mothers adopted a vigorous use of the past and future references (especially the near future) starting from session 1 . Thus, there was a clear delay in the children's onset of displaced temporal reference to the past and future in comparison with the mothers', especially in utterances without pointing. From 24 months onward, children's use of references to 


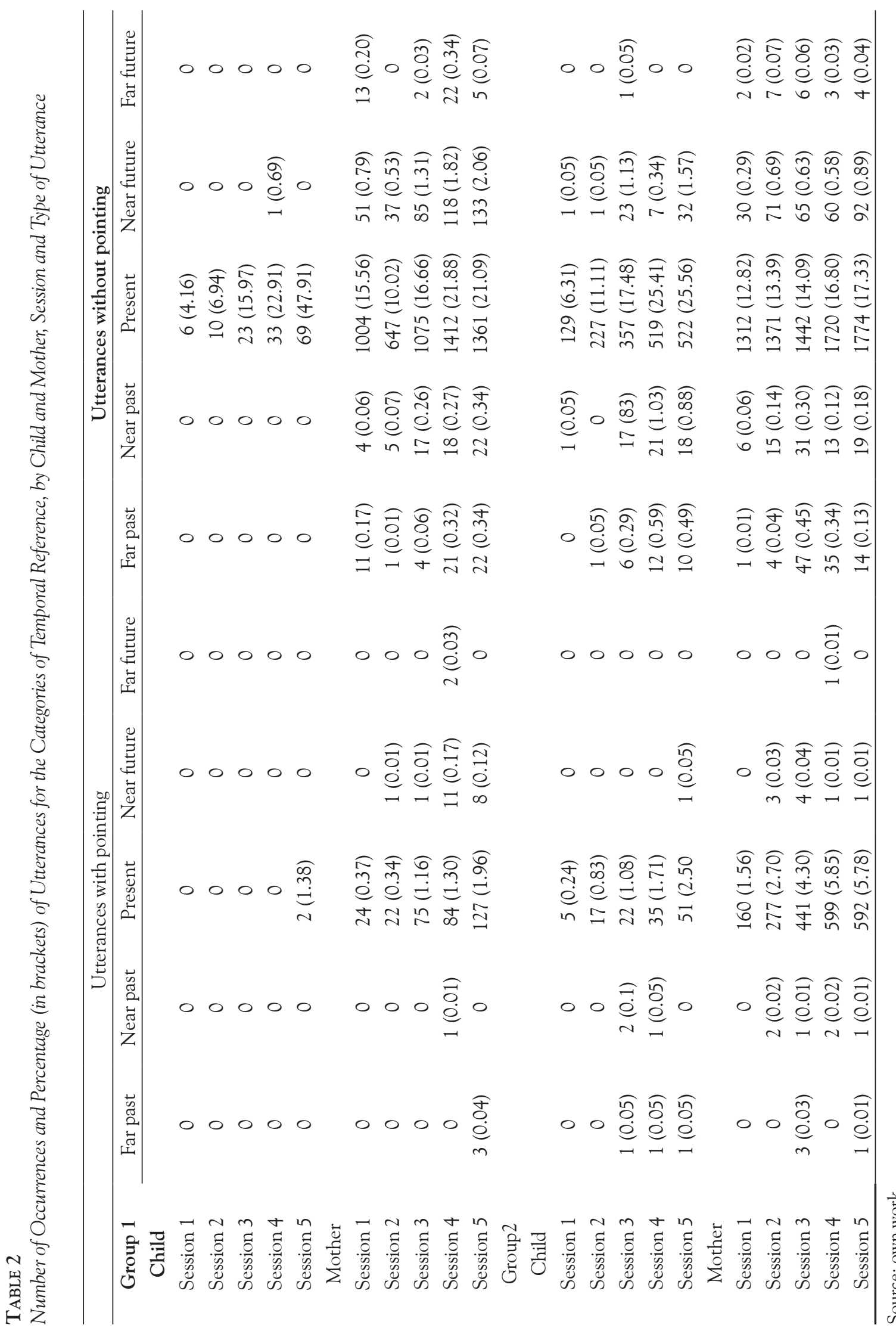


the past and future in utterances with pointing remained at a very low level, whereas it increased steadily throughout the sessions, especially from 30 months (with the exception of the far future), when pointing was not present. During the same time period, mothers' use of displaced temporal references was still practically confined to the near past and near future in sentences with pointing, while it increased from 24 months onward for the near past and near future - and less clearly so from 27 months onward for far past and far future - in sentences without pointing.

\section{Group Comparisons of Temporal References}

Figures 1 and 2 show the distribution of the percentage of utterances with and without a pointing gesture of each category of temporal reference produced by children and mothers for each age group. To compare the five categories of temporal reference, a series of t-tests were performed. First, we compared the overall distribution of the temporal categories/frames in the utterances with and without pointing, independently of the age groups and mother/child variables. The results showed that the distribution was quite similar. In utterances with pointing, the present frame was used significantly more than the near future $(t(15)=3.69, p$ $=0.002)$, far future $(t(15)=3.73, p=0.002)$, near past $(t(15)=3.73, p=0.002)$, and far past $(t(15)$ $=3.73, p=0.002)$. The near future was used more than the far future $(t(15)=2.99, p=0.009)$. In utterances without pointing, the results showed that the present frame was used significantly more than the near future $(t(15)=8.25, p=<0.001)$, far future $(t(15)=8.32, p<0.001)$, near past $(t(15)$ $=8.44 ; p<0.001)$, and far past $(t(15)=8.31, p<$ 0.001). The near future was used significantly more than the far future $(t(15)=3.61, p=0.003)$, near past $(t(15)=3.38, p=0.004)$, and far past $(t(15)$ $=3.42, p=0.004)$. Finally, the far past was used significantly more than the far future $(t(15)=-2.25$, $p=0.039$ ). In sum, participants were more likely to use the present frame and close temporal references (near past and especially near future) than the far time frames, with the far future being the least significantly used frame.

Second, we compared mothers' and children's production of the five categories of temporal reference for the two groups. The results showed that

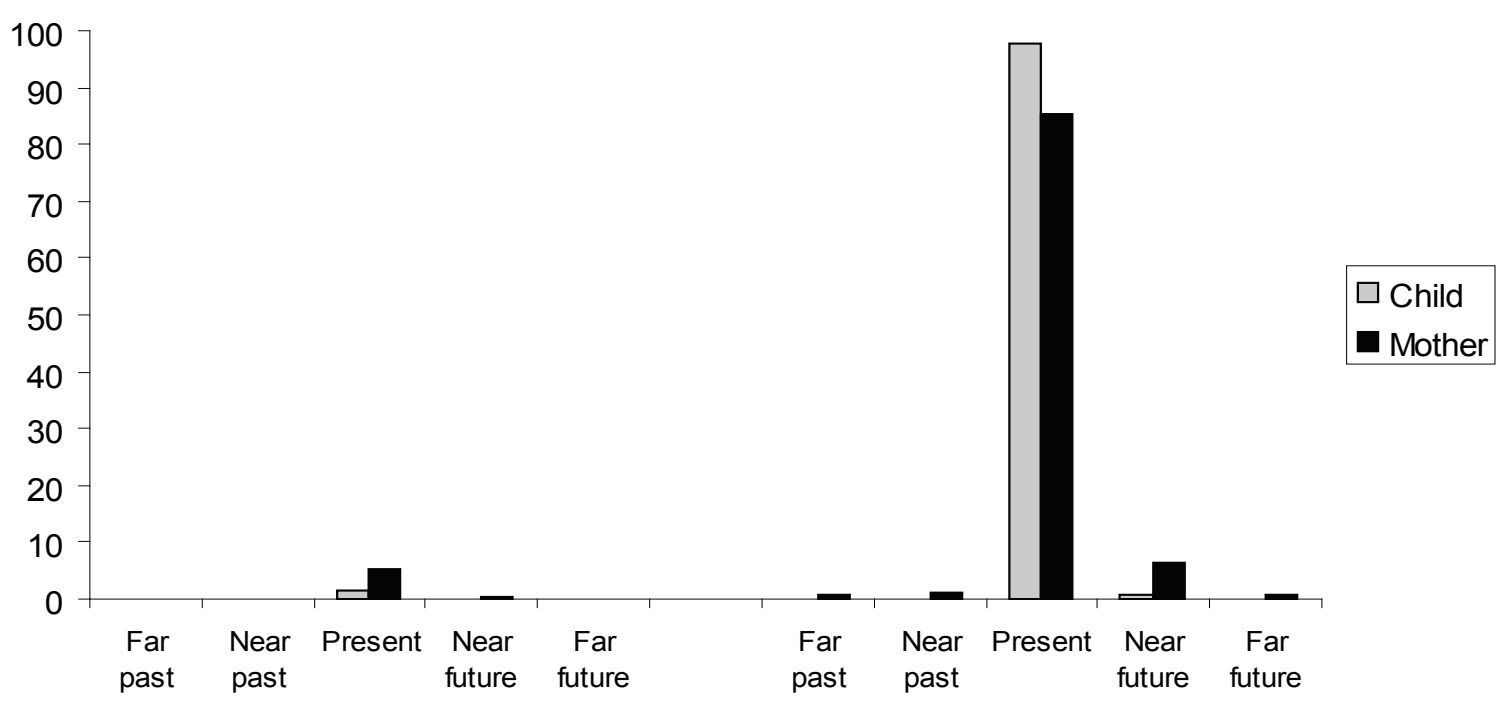

Figure 1. Mean percentage of utterances with and without pointing corresponding to the categories of temporal reference in Group 1 (\% are calculated with respect to the total number of utterances).

Source: own work 


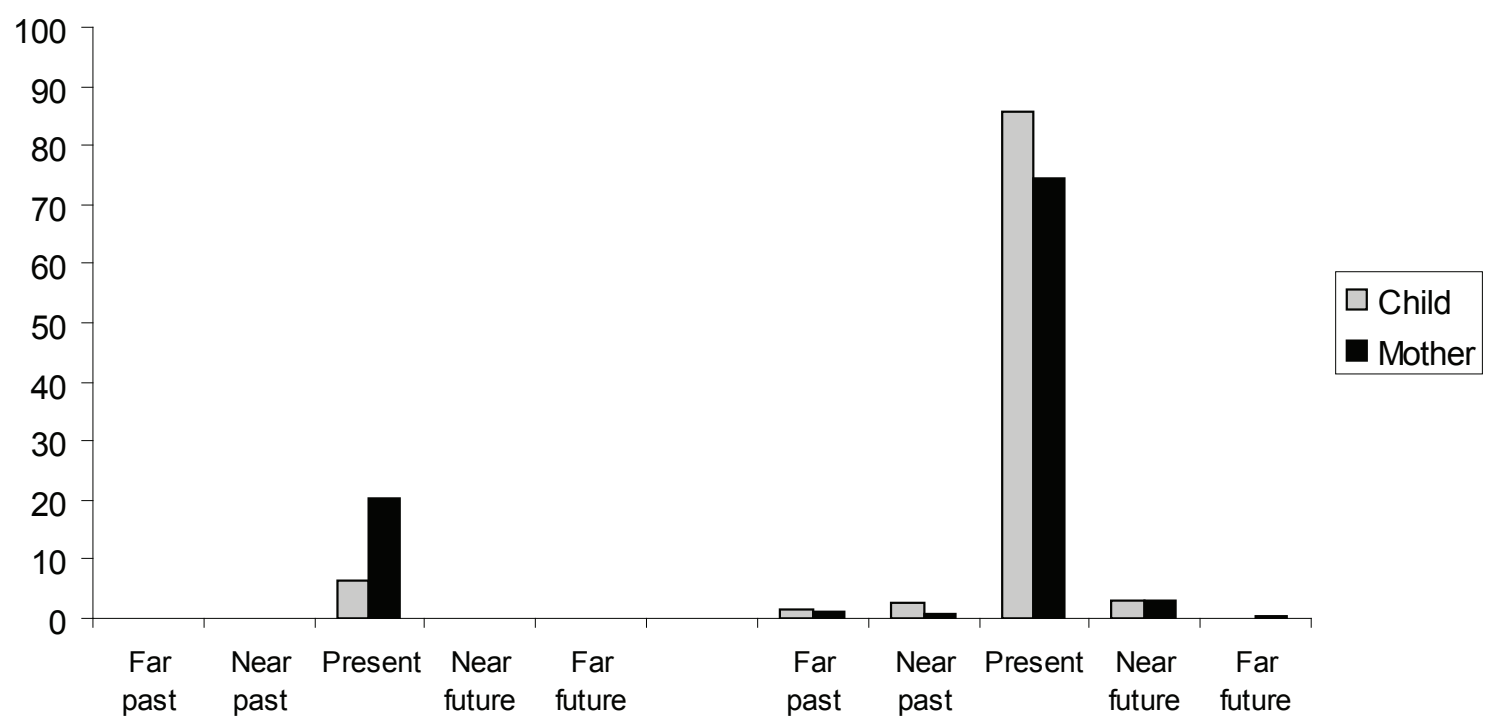

Figure 2. Mean percentage of utterances with and without pointing corresponding to the categories of temporal reference in Group 2 (\% are calculated with respect to the total number of utterances).

Source: own work

the mothers' use of present and near future frames was significantly higher than that of children $(t(14)$ $=-2.23, p=0.042 ; t(14)=-2.81, p=0.20$, respectively) in utterances with pointing. Similar analyses were then made for each age group. In Group 1, the results showed that the mothers' use of the present frame with pointing $(t(6)=-2.81, p=0.018)$, the near future with pointing $(t(6)=-4.73, p=0.018)$, and the near future without pointing $(t(6)=-3.23$, $p=0.018)$ was significantly higher than that of children. Thus, mothers tended to work more than younger children in the 'soon to happen' referential time frame. In Group 2, the results showed that the mothers' use of the present frame $(t(6)=-2.57, p=$ 0.042 ) was significantly higher than that of children in utterances with pointing. There were no other significant mother-child differences, indicating that the pattern of temporal reference was quite similar between mothers and children in Group 2.

Third, some group comparisons were found to be significant. Children in Group 2 used the present frame more than children in Group $1(t(6)=-3.93$, $p=0.008)$ in utterances with pointing. Likewise, mothers in Group 2 used the present frame more than mothers in Group $1(t(6)=-2.81, p=0.03)$ in utterances with pointing. Finally, mothers in Group 1 used the near future more than mothers in Group $2, t(6)=2.76, p=0.033)$ in utterances with pointing.

\section{Mother/Child Correlation of Temporal Reference}

To explore the relationships between the five categories of temporal reference in the total number of utterances produced by mother and child, a set of Spearman rank-order correlations was computed across the ten observation points spanning the two age groups (data from the four mothers and the four children at each observation point were accumulated). The mothers' and children's use of the present frame was strongly and positively correlated across all observation points (Table 3). Mothers' use of the present frame was positively correlated with the children's use of the near future frame. Mothers' use of the near past was positively correlated with the children's use of present and near future frames. These results indicate that mother-child correlations were more likely to occur around the present time frame and its immediate temporal surroundings. 
To further examine the impact of mother and child pointing on the mother/child relations of temporal reference, Kendall partial-rank correlations were performed for each of the correlations reported in Table 3. In this way we can analyze to what extent the absence of pointing increases the production of displaced references accordingly in the mother and child. All correlations remained significant after mother or child pointing was partialled out. Moreover, the correlations between mother and child references to the near future and far future frames became statistically significant when mother or child pointing was partialled out $\left(0.87^{* *}\right.$ and $0.86^{* *}$, respectively; $0.87^{* *}$ and $0.86^{* *}$, respectively). This was also the case for the correlations between mothers' use of the far future and children's use of the near future frames (0.69* and $0.68 *$, respectively), and correlations between mothers' use of the near future and children's use of the present frame $(0.89 * *$ and $0.86 * *$, respectively). And finally, the mothers' use of the far past and children's use of the near past became statistically reliable only when child pointing was partialled out $(0.67 *)$. These results indicate that stronger mother/child co-variation appeared with respect to the use of future frames after controlling for the presence of the combined use of pointing plus speech utterances.

\section{Discussion}

The present study longitudinally compared mothers and their children from 12 to 36 months of age with respect to their use of verbal and gestural references to objects, during the performing of everyday routines. Overall, children and mothers showed a sustained level of communication during long periods of observation (an average of 3.5h per dyad). As could be expected, mothers produced four times more utterances than their children, and the total amount of utterances was quite impressive (26.153 in 28.5 hours of recording). Mothers and children produced fewer utterances accompanied by a pointing gesture (26.8\% and $7.3 \%$, respectively) than utterances without pointing. Pointing + speech combinations represented $34.1 \%$ of all mother-child communication recorded in this study, indicating that the early communicative environment is multimodal (Meltzoff \& Kuhl, 1994).

Overall mothers and children used more verbs referring to the present frame than to the past and future frames. The children's first reference to a present frame was at session 5 in utterances with pointing, and at session 1 in utterances without pointing. It was difficult to establish the temporal reference in the children's first combinatorial pointing + speech forms, because of their poor production of verbs in this format. In addition, younger children mainly produced verbs in one form only (e.g. Veneziano \& Parisse, 2010), but in many cases we could infer that they were using the present frame by looking at the context. Mothers were able to produce references to the present frame from the first session, under both conditions (with and without pointing).

The younger children's references to the past and future were null, regardless of the type of ut-

TABLE 3

Spearman Rank-Order Correlations between Mother and Child Categories of Temporal Reference

\begin{tabular}{lccccc}
\hline & \multicolumn{6}{c}{ Child } & & & \\
\cline { 2 - 6 } Mother & Far past & Near past & Present & Near future & Far future \\
\hline Far past & 0.34 & $0.31\left(\mathrm{~ns} ; 0.67^{*}\right)$ & 0.62 & 0.49 & 0.6 \\
Near past & -0.1 & -0.05 & $0.74^{* *}$ & $0.83^{* *}$ & 0.36 \\
Present & 0.35 & 0.22 & $0.87^{* *}$ & $0.77^{* *}$ & 0.54 \\
Near future & -0.22 & -0.46 & $0.55\left(0.89^{* *} ; 0.86^{* *}\right)$ & $0.63\left(0.87^{* *} ; 0.86^{* *}\right)$ & 0.04 \\
Far future & -0.06 & -0.28 & 0.23 & $0.26\left(0.69^{*} ; 0.68^{*}\right)$ & $0.37\left(0.87^{* *} ; 0.86^{* *}\right)$ \\
\hline
\end{tabular}

$* p<0.05 ; * p<0.01$. In bold face are those correlations that remained significant or became reliable (in brackets) after mother or child speech with pointing were partialled out.

Source: own work 
terances, indicating a lack of ability to talk about objects, persons and events that are not in the present time frame. Mothers' references to the past and future frames were also very limited at these ages in utterances with pointing, but they started to use displaced temporal references from session 1 when pointing was not present. This is an interesting case in which mothers provide children with exposure to temporal language without necessarily expecting their children to fully understand it (Hudson, 2006; Sachs, 1983). According to the literature, children's references to the past emerge over the third year of life (Valian \& Aubry, 2005; Schütze $\&$ Wexler, 2000). In our study, children's references to the past emerged at 30 months in utterances with pointing while remaining thereafter at a very low level, whereas they emerged at 24 months and steadily increased thereafter in utterances without pointing. Children's references to the near future emerged at 24 months of age in utterances without pointing. No references were made to the far future frame. Preschool children still confuse the near future with the recent past, suggesting that temporal proximity around the present frame is a more salient construct at this age than the distinction between past and future (Friedman, 2003). Mothers' displaced temporal references were practically confined to the near past and near future frames in utterances with pointing, and from 27 months onward, extended to the far past and far future frames in utterances without pointing, suggesting a clear modulation with respect to the presence of a pointing.

The pattern of temporal immediate reference was remarkably similar in mothers and children, suggesting that mothers adjust very well to their children across ages. Concerning displaced temporal reference, mothers in Group 1 used the near future frame more than mothers in Group 2, indicating that they were preparing the younger children to frame the events that were going to occur next, especially in utterances with pointing, where children have to overcome the constraint to the 'now' objects.

Evidence of a co-development of mother-child temporal references across ages was strong, and very much dependent on the presence of pointing. Without controlling for the mother and child pointing, mother-child correlations were more likely to occur around the present time frame and its immediate temporal surroundings. However, after mother or child pointing was partialled out, another set of correlations appeared that had to do with the increasing mother-child use of near and far future frames. This result supports studies by Lucariello and Nelson (1987) and by Benson (1997) in which parents talked with young children about the future more than they talked about the past.

In conclusion, children would be less inclined to use pointing + speech combinations in situations involving present references in the younger group and displaced references in the older group, probably because it is more difficult to them to understand how to refer to something using combined means. Children were more likely to produce present references in the young group and displaced references in the older group when utterances were produced without pointing. Mothers closely preceded or accompanied the children's verbal and gestural referential production to either immediate or displaced referents across ages, indicating that they systematically engage their children in talking about the present and especially the future. This ability is essential to enrich joint activity with processes of planning, decision-making, and goal attainment (Benson, 1997; Hudson, 2006). All these findings suggest a close relationship between patterns of language acquisition, referential production and mother-child communication.

\section{References}

Benson, J. B. (1997). The development of planning: It's about time. In S. L. Friedman \& E. K. Scholnick (Eds.), The developmental psychology of planning: Why, how, and when do we plan? (pp. 43-75). Mahwah, NJ: Erlbaum.

Eisenberg, A. R. (1985). Learning to describe past experiences in conversation. Discourse Processes, $8(2), 177-204$.

Friedman, W. J. (2003). The development of a differentiated sense of the past and the future. In R. Kail 
(Ed.), Advances in child development and behavior (Vol. 31, pp. 229-269). New York: Academic Press.

Gallaway, C., \& Richards, B. J. (Eds.). (1994). Input and interaction in language acquisition. Cambridge, UK: Cambridge University Press.

Harris, M., Jones, D., \& Grant, J. (1983). The nonverbal context of mothers' speech to infants. First Language, $4(10), 21-30$.

Hockett, C. F. (1960). Logical considerations in the study of animal communication. In W. E. Lanyon \& W. N. Tavolga (Eds.), Animal sounds and animal communication (pp. 392-342). Washington, DC: American Institute of Biological Studies.

Hudson, J. A. (2002). 'Do you know what we're going to do this summer?' Mothers' talk to young children about future events. Journal of Cognition and Development, 3(1), 49-71.

Hudson, J. (2006). The development of future time concepts through mother-child conversation. Journal of Developmental Psychology, 52(1), 70-95.

Lewis, M. M. (1934). The beginning of reference to past and future in a child's speech. British Journal of Educational Psychology, 7, 39-55.

Lucariello, J., \& Nelson, K. (1987). Remembering and planning talk between mothers and children. Discourse Processes, 10(3), 219-235.

Meltzoff, A. N., \& Kuhl, P. K. (1994) Faces and speech: Intermodal processing of biological relevant signals in infant and adults. In D. J. Lewkowick \& R. Lickliter (Eds), The development of intersensory perception: Comparative perspectives (pp. 335-370). Hillsdale, NJ: Erlbaum.

Morford, J. P., \& Goldin-Meadow, S. (1997). From here and now to now and then: The development of displaced reference in homesign and English. Child Development, 68(3), 420-435.

Özçalışkan, S.., \& Goldin-Meadow, S. (2009). When gesture-speech combinations do and do not index linguistic change. Language and Cognitive Processes, 28(24), 190-217.

Rojas, N. (2003). Early acquisition of Spanish verb inflexion. A usage-based account .Psychology of Language and Communication, 7(1), 17-36.

Sachs, J. (1983). Talking about the there and then: The emergence of displaced reference in parent-child discourse. In K. E. Nelson (Ed.), Children's Language (Vol. 4, pp. 1-28). Hillsdale, NJ: Erlbaum.

Schütze, C. T., \& Wexler, K. (2000). An elicitation study of young English children's knowledge of tense: Semantic and syntactic properties of optional infinitives. In S. C. Howell, S. A., Fish \& T. Keith-Lucas (Eds.), Proceedings of the 24th Annual Boston University Conference on Language Development (Vol. 2, pp. 669-683). Somerville, MA: Cascadilla Press.

Valian, V. (2006). Young children's understanding of present and past tense. Language and Learning Development, 2(4), 251-276.

Valian, V., \& Aubry, S. (2005). When opportunity knocks twice: Two-year-olds' repetition of sentence subjects. Journal of Child Language, 32(3), 617-641.

Veneziano, F., \& Parisse, C. (2010). The acquisition of early verbs in French: Assessing the role of conversation and or child-directed speech. First Language, 30(3-4), 287-311.

Wilson, S. (2003). Lexically specific constructions in the acquisition of inflection in English. Journal of Child Language, 30(1), 75-115. 
